\title{
SYSTEM-OF-SYSTEMS SITUATIONAL AWARENESS EFFECTIVENESS USING AHP
}

\author{
Rahim Jassemi-Zargani Fredrick Lichacz Nathan Kashyap \\ Defence Research \& Development Canada - Ottawa \\ Space \& ISR Application Section/ISR Concept \& Integration Group \\ 3701 Carling Avenue, Ottawa, Ontario, Canada K1A 0Z4, CANADA \\ rahim.jassemi@drdc-rddc.gc.ca / fred.lichacz@drdc-rddc.gc.ca / nathan.kashyap@drdc- \\ rddc.gc.ca
}

\begin{abstract}
The integration of system-of-systems (SoS) data into shared situational awareness (SA) involves a complex interplay between a collection of sensors, network architectures and exploitation capability. To achieve the desired level of SA (i.e., information superiority) and improve the sense-to-act cycle requires an environment that is agile, interoperable, robust and efficient. To that end, this paper presents an integration concept evaluation methodology based on an Analytical Hierarchy Process (AHP) that uses technical and cognitive elements to assess the degree to which a system-of-systems concept can facilitate shared SA.
\end{abstract}

Keywords: Situational Awareness, System-of-Systems, Performance Evaluation, Decision Making, AHP.

\section{Introduction}

Technology is a key driver in achieving capabilities which involves the exploitation of data, dissemination of information and better decision making. In evaluating technological capabilities, the physical system as well as the service providing the transfer of information in the framework must be considered. However, a complete evaluation of the SoS concept's ability to facilitate SA cannot end with the technology alone. The technology does not work in isolation but must interface with human operators. As such, there are human factors (HF) elements that need to be evaluated within the performance of the service providing the data (i.e., imagery, positions) and the capabilities of the sensor platform producing the data for the service. Accordingly, a complete evaluation of the SoS concept must include an analysis of the technical elements of the concept and the concept's ability to meet the needs of the user; that is the operators' perception of how well the SoS concept facilitates their decision-making ability. The following section and subsections of this paper will present the proposed SoS concept evaluation process based on SA effectiveness. 


\section{SoS SA Concept Evaluations}

The challenge for a SoS concept evaluation process is to develop efficient and reliable methodologies and metrics to accurately evaluate the concept's operational effectiveness. This paper presents a method that has been developed to evaluate the SA effectiveness based on an Analytical Hierarchical Process (AHP) [1]. Moreover, the approach taken for evaluating and assessing SA through metric evaluation has potential applications for procuring and deploying any SoS concept. The use of scenarios can be applied to perform the evaluation of SA based on a SoS capability. Sets of metrics have been identified in this process, one based on a scenario and the other being scenario independent. This process relies on a hierarchical decomposition of the objectives into lower-level measures of performance (MOPs). The MOPs are combined using weights obtained through subject matter experts' evaluation of their relative importance. The process for evaluation is shown conceptually in Figure 1. The evaluation assesses the relative performance of a SoS using selected metrics to evaluate how well mission requirements are being met.

\section{Hierarchical Evaluation Process}

The first step in the hierarchical evaluation process is to decompose the mission requirements into one or more essential elements or factors. For example, the mission requirement could assess a situation within an area of responsibility; both technical and HF criteria are used in the evaluation process.

\subsection{Technical and Human Factors Criteria}

The technical scenario's dependent and independent elements that relate to measuring or assessing the capabilities of the physical system are listed in Table 1. The scenario dependent elements are dynamic elements that change based on scenario. In contrast, independent elements are more systems related general capabilities. For every case or concept, the dependent elements play a more important role than the independent elements, because not every concept works the best for any scenario.

The HF component of this evaluation focuses on the operators' perceptions of the effectiveness of the SoS concept. This cognitive evaluation is divided into hard and soft elements (see Table 1). The hard elements pertain to the operators' perception of the quality, quantity, completeness, and latency of the data they receive from the systems. The soft elements pertain to meta-cognitive aspects of the decision-making process. As such, this part of the evaluation will assess the operators' trust in the system, their views on whether the system can meet the information requirements to produce the desired level of SA, and how well the concept facilitates efficient dissemination of information.

\subsection{Influence Diagram}

To evaluate SoS concepts, an aggregation methodology is used where criteria and MOPs are grouped together. The aggregation of both sets of metrics are applied and compared using a multi-decision criteria process called AHP to assess the degree to which a SoS concept can facilitate shared SA. The influence diagram was developed based on HF and technical criteria and sub-criteria (see Figure 1). 
ISAHP Article: A Style Guide for Paper Proposals To Be Submitted to the International Symposium on the Analytic Hierarchy Process 2018, Hong Kong, HK.

Table 1. Technical and Human Factor Criteria

\begin{tabular}{|c|c|}
\hline \multirow{2}{*}{$\begin{array}{r}\text { Technical } \\
\text { Scenario Dependent }\end{array}$} & Human Factor \\
\hline & Cognitive- Hard Elements \\
\hline Tasking & Quality \\
\hline Detection & Quantity \\
\hline Tracking & Latency \\
\hline Processing & Completeness \\
\hline Exploitation & \\
\hline Dissemination & \\
\hline Scenario Independent & Cognitive- Soft Elements \\
\hline Agility & Info Requirements \\
\hline Dependability & Trust \\
\hline Affordability & Flexibility \\
\hline Interoperability & Shared SA \\
\hline Availability & Info Dissemination \\
\hline
\end{tabular}

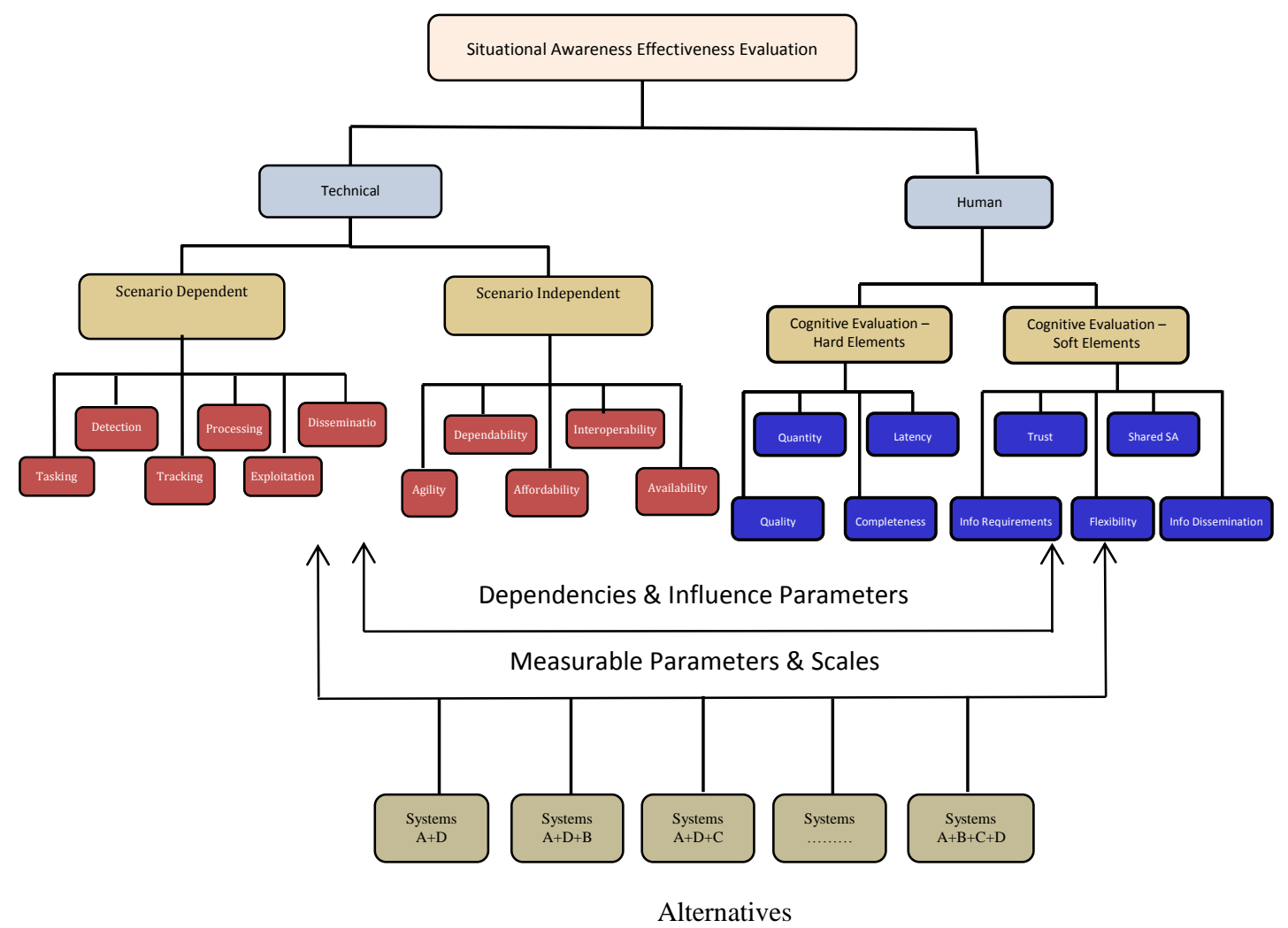

Figure 1. Situational Awareness Effectiveness Evaluation Influence Diagram 
ISAHP Article: A Style Guide for Paper Proposals To Be Submitted to the International Symposium on the Analytic Hierarchy Process 2018, Hong Kong, HK.

\subsection{Evaluation Process}

The evaluation process was conducted in two steps: first, the technical merit is evaluated and then feedback is provided until the technical merits are achieved. The second step for the SoS concept evaluation is based on HF (see Figure 2). The outcome of HF evaluation will be feedback provided to the technical level in order to adjust or restructure the SoS concepts until the both the technical and HF SoS concept can satisfy all of the merits requirements. The comparison between technical and human factor outcomes will be evaluated using the RMSE. Minimizing the RSME value will present the confirmation of technical evaluation by HF evaluation.

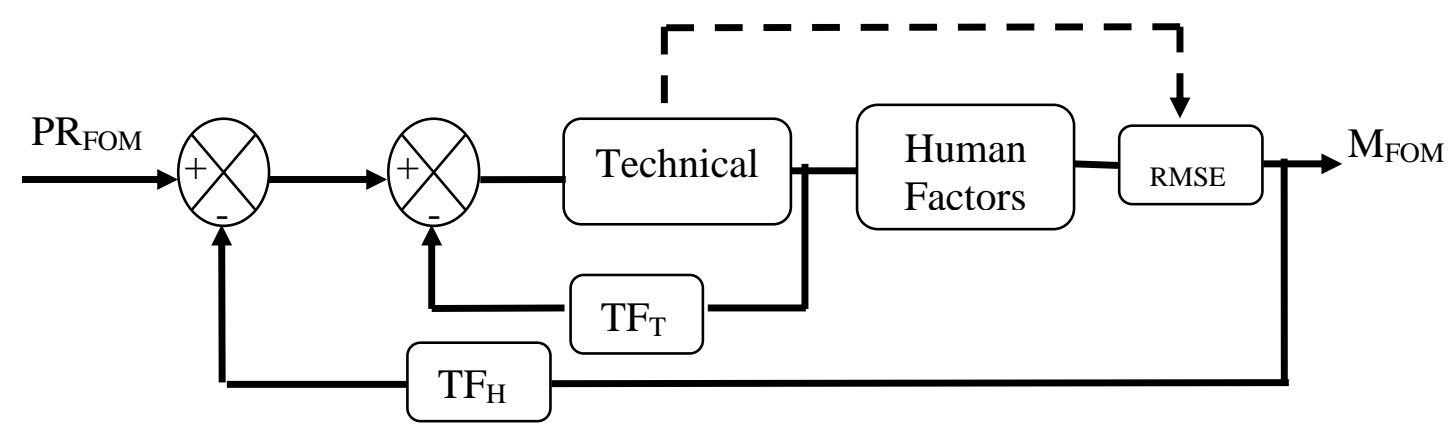

Figure 2. SoS Performance Process

Where:

- $\quad \mathrm{PR}_{\mathrm{FOM}}=$ Performance Requirements FOM

- $\quad \mathrm{FOM}=$ Figures of Merits

- $\quad \mathrm{M}_{\mathrm{FOM}}=$ Measured FOM

- $\quad \mathrm{TF}_{\mathrm{T}}=$ Transfer Function (Technical)

- $\quad \mathrm{TF}_{\mathrm{HF}}=$ Transfer Function (Human Factor)

- $\quad$ RMSE $=$ Root Mean Square Error

The evaluation process will be applied to system and SOS levels. In this paper, the evaluation used at system level first, then based on result, concept of SOS will be developed and evaluated.

\section{Analytical Hierarchy Process (AHP)}

The SoS evaluation is conducted based on the Analytical Hierarchy Process [1]. The calculation of overall evaluation $\left(S_{i}\right)$ is conducted based on the following equation established from the influence diagram in Figure 1 [2]. 
ISAHP Article: A Style Guide for Paper Proposals To Be Submitted to the International Symposium on the Analytic Hierarchy Process 2018, Hong Kong, HK.

$$
s_{i}=\sum_{j=1}^{m} \sum_{k=1}^{n} C_{i, j . k} w_{s}
$$

Where:

- $\quad i=0 \ldots \mathrm{P}(\mathrm{P}=$ total number of SoS concepts/Alternatives $)$

- $\quad j=1 \ldots \mathrm{m}(\mathrm{m}=$ total number of criteria)

- $\quad k=1 \ldots \mathrm{n}(\mathrm{n}=$ total number of sub-criteria for each criteria)

- $\quad \mathrm{C}_{i, j, k}=$ Performance score of each sub-criteria from Table 4.

- $\quad \mathrm{w}_{c}=$ Weight for each criteria from Table 3.

\section{SA Results and Analysis}

By applying the AHP process, the creation of the comparison matrix for technical and human factors was developed by subject matter experts (SME) (see Table 2).

Table 2. Comparison matrix for technical and human factor criteria

\begin{tabular}{|c|c|c|c|c|c|c|c|c|c|c|c|c|c|c|}
\hline & \multicolumn{14}{|c|}{ Technical } \\
\hline & & 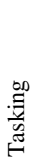 & 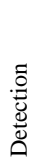 & 总 & 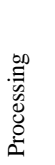 & 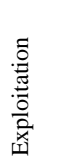 & 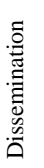 & & & $\frac{\vec{t}}{\stackrel{\overrightarrow{0}}{\alpha}}$ & 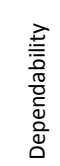 & $\begin{array}{l}\frac{7}{ \pm} \\
\overline{0} \\
\frac{\pi}{0} \\
\frac{0}{0} \\
\frac{4}{4}\end{array}$ & 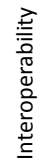 & $\begin{array}{l}\frac{\vec{t}}{\overline{\overline{0}}} \\
\frac{\sqrt{0}}{\bar{\pi}} \\
\frac{\pi}{2}\end{array}$ \\
\hline \multirow{8}{*}{ 趌 } & Tasking & 1 & 0.5 & 0.33 & 0.33 & 0.14 & 1.0 & \multirow{6}{*}{ 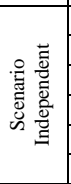 } & Agility & 1.0 & 2.0 & 1.0 & 1.0 & 0.5 \\
\hline & Detection & 2.0 & 1.0 & 0.50 & 0.50 & 0.20 & 2.0 & & Dependability & 0.5 & 1.0 & 0.5 & 0.5 & 0.5 \\
\hline & Tracking & 2.0 & 1.0 & 1.00 & 1.00 & 0.50 & 3.0 & & Affordability & 1.0 & 2.0 & 1.0 & 2.0 & 1.0 \\
\hline & Processing & 3.0 & 2.0 & 1.00 & 1.00 & 0.50 & 3.0 & & Interoperability & 1.0 & 2.0 & 0.5 & 1.0 & 2.0 \\
\hline & Exploitation & 7.0 & 5.0 & 2.00 & 2.00 & 1.00 & 7.0 & & Availability & 2.0 & 2.0 & 1.0 & 0.5 & 1.0 \\
\hline & Dissemination & 1.0 & 0.5 & 0.33 & 0.33 & 0.14 & 1.0 & & & & & & & \\
\hline & \multicolumn{14}{|c|}{ Human Factor } \\
\hline & & $\frac{\frac{\pi}{\sqrt{0}}}{\frac{\pi}{\sigma}}$ & 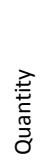 & ป̀ & 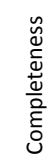 & & & & & 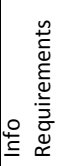 & $\stackrel{\frac{n}{2}}{\underline{2}}$ & $\begin{array}{l}\frac{\vec{Z}}{\bar{a}} \\
\frac{\bar{a}}{x} \\
\frac{\omega}{4}\end{array}$ & $\begin{array}{l}\frac{\pi}{n} \\
0 \\
\frac{1}{\pi} \\
\frac{\pi}{5} \\
\frac{\pi}{n}\end{array}$ & 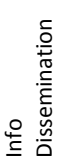 \\
\hline \multirow[t]{5}{*}{ t } & Quality & 1.0 & 2.0 & 1.0 & 2.0 & & & \multirow{5}{*}{ 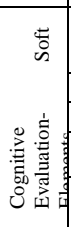 } & $\begin{array}{l}\text { Info } \\
\text { Requirements }\end{array}$ & 1.0 & 1.0 & 2.0 & 1.0 & 2.0 \\
\hline & Quantity & 0.5 & 1.0 & 2.0 & 0.5 & & & & Trust & 1.0 & 1.0 & 2.0 & 2.0 & 4.0 \\
\hline & Latency & 1.0 & 0.5 & 1.0 & 0.5 & & & & Flexibility & 0.5 & 0.5 & 1.0 & 2.0 & 1.0 \\
\hline & Completeness & 0.5 & 2.0 & 2.0 & 1.0 & & & & Shared SA & 1.0 & 0.5 & 0.5 & 1.0 & 2.0 \\
\hline & & & & & & & & & $\begin{array}{l}\text { Info } \\
\text { Dissemination }\end{array}$ & 0.5 & 0.25 & 1.0 & 0.5 & 1.0 \\
\hline
\end{tabular}

Based on the comparison matrix, the measured level weights have been calculated within a consistency threshold of $10 \%$. The weights for measured level criteria are shown in Table 3. The weights for sub-criteria are selected by user. 
ISAHP Article: A Style Guide for Paper Proposals To Be Submitted to the International Symposium on the Analytic Hierarchy Process 2018, Hong Kong, HK.

Table 3. The weights of each criteria and sub-criteria

\begin{tabular}{|c|c|c|c|c|}
\hline Criteria & Sub-Criteria & Weights & $\begin{array}{l}\text { Measured level- } \\
\text { Criteria }\end{array}$ & Weights \\
\hline \multirow{11}{*}{ Technical } & \multirow{6}{*}{$\begin{array}{l}\text { Scenario } \\
\text { Dependent }\end{array}$} & \multirow{6}{*}{6} & Tasking & 0.058 \\
\hline & & & Detection & 0.100 \\
\hline & & & Tracking & 0.187 \\
\hline & & & Processing & 0.187 \\
\hline & & & Exploitation & 0.410 \\
\hline & & & Dissemination & 0.058 \\
\hline & \multirow{5}{*}{$\begin{array}{l}\text { Scenario } \\
\text { Independent }\end{array}$} & \multirow{5}{*}{.4} & Agility & 0.191 \\
\hline & & & Dependability & 0.105 \\
\hline & & & Affordability & 0.251 \\
\hline & & & Interoperability & 0.226 \\
\hline & & & Availability & 0.227 \\
\hline \multirow{9}{*}{$\begin{array}{l}\text { Human } \\
\text { Factor }\end{array}$} & \multirow{4}{*}{$\begin{array}{c}\text { Cognitive } \\
\text { Evaluation- Hard } \\
\text { Elements }\end{array}$} & \multirow[b]{4}{*}{.5} & Quality & 0.341 \\
\hline & & & Quantity & 0.202 \\
\hline & & & Latency & 0.179 \\
\hline & & & Completeness & 0.278 \\
\hline & \multirow{5}{*}{$\begin{array}{c}\text { Cognitive } \\
\text { Evaluation- Soft } \\
\text { Elements }\end{array}$} & \multirow{5}{*}{.5} & Info Requirements & 0.244 \\
\hline & & & Trust & 0.315 \\
\hline & & & Flexibility & 0.168 \\
\hline & & & Shared SA & 0.167 \\
\hline & & & Info Dissemination & 0.107 \\
\hline
\end{tabular}

The measurements at system level have been shown in Table 4, and based on these measurements and the weights from Tables 3, the performance of each system been computed. The results are shown in Figure 3. The measurement for system-of-systems also been collected and analyzed and the results are shown in Figure 4

Table 4. Performance measurements

\begin{tabular}{|c|c|c|c|c|c|c|c|c|c|c|c|}
\hline & \multicolumn{11}{|c|}{ Technical } \\
\hline & Systems & A & B & $\mathrm{C}$ & D & & & A & B & $\mathrm{C}$ & $\mathrm{D}$ \\
\hline \multirow{8}{*}{ 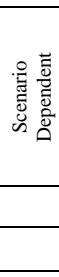 } & Tasking & 0.32 & 0.26 & 0.16 & 0.26 & \multirow{6}{*}{ 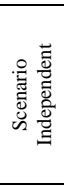 } & Agility & 0.16 & 0.24 & 0.24 & 0.36 \\
\hline & Detection & 0.37 & 0.16 & 0.21 & 0.26 & & Dependability & 0.25 & 0.29 & 0.21 & 0.25 \\
\hline & Tracking & 0.45 & 0.20 & 0.15 & 0.20 & & Affordability & 0.38 & 0.14 & 0.14 & 0.33 \\
\hline & Processing & 0.30 & 0.22 & 0.22 & 0.26 & & Interoperability & 0.28 & 0.24 & 0.24 & 0.24 \\
\hline & Exploitation & 0.37 & 0.19 & 0.19 & 0.26 & & Availability & 0.23 & 0.27 & 0.15 & 0.35 \\
\hline & Dissemination & 0.28 & 0.24 & 0.32 & 0.16 & & & & & & \\
\hline & \multicolumn{11}{|c|}{ Human Factor } \\
\hline & & $\mathrm{A}$ & $\mathrm{B}$ & $\mathrm{C}$ & $\mathrm{D}$ & & & $\mathrm{A}$ & $\mathrm{B}$ & $\mathrm{C}$ & $\mathrm{D}$ \\
\hline \multirow[b]{5}{*}{ 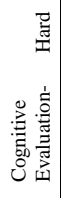 } & Quality & 0.26 & 0.26 & 0.21 & 0.26 & \multirow[t]{5}{*}{ 吾 } & $\begin{array}{l}\text { Info } \\
\text { Requirements }\end{array}$ & 0.26 & 0.23 & 0.29 & 0.23 \\
\hline & Quantity & 0.19 & 0.29 & 0.24 & 0.29 & & Trust & 0.22 & 0.22 & 0.30 & 0.26 \\
\hline & Latency & 0.38 & 0.19 & 0.24 & 0.19 & & Flexibility & 0.26 & 0.22 & 0.26 & 0.26 \\
\hline & Completeness & 0.19 & 0.23 & 0.27 & 0.31 & & Shared SA & 0.33 & 0.25 & 0.21 & 0.21 \\
\hline & & & & & & & $\begin{array}{l}\text { Info } \\
\text { Dissemination }\end{array}$ & 0.24 & 0.28 & 0.20 & 0.28 \\
\hline
\end{tabular}


ISAHP Article: A Style Guide for Paper Proposals To Be Submitted to the International Symposium on the Analytic Hierarchy Process 2018, Hong Kong, HK.

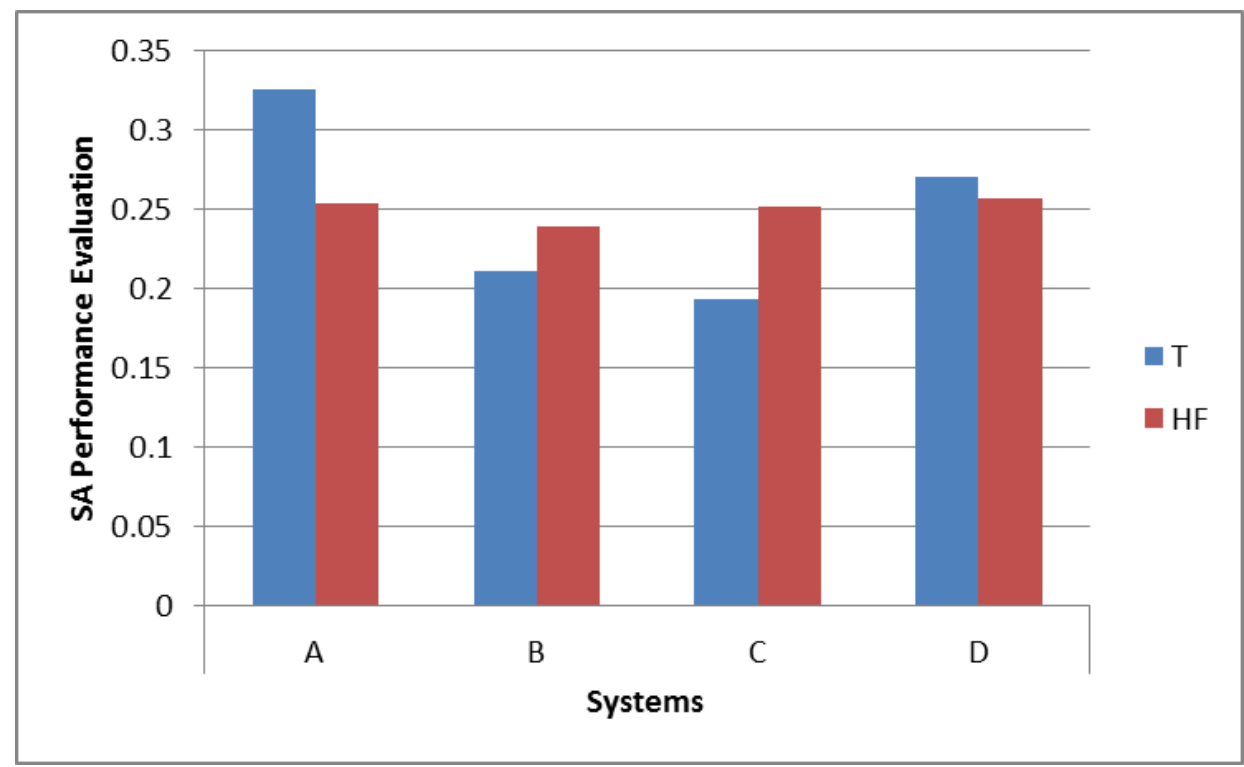

Figure 3. System level evaluation (T for Technical, HF for Human Factor)

Root Mean Square Error (RMSE) was computed for comparison between technical and human factor evaluation. The lower RSME is indication of validation of technical performance evaluation by human factor evaluation.

$$
R M S E=\sqrt{\frac{\sum_{i=1}^{n}\left(H F_{i}-T_{i}\right)^{2}}{n}}
$$

The RMSE value for system based evaluation between the technical and an HF result was 0.0488. This value shows the consistency between the technical and HF evaluations, which is acceptable value $(<10 \%)$ to proceed to SoS level evaluation.

Based on the system level evaluation, systems $A$ and $D$ performance better than the other two systems; therefore, the system A and D will be considered as the base system for all the SoS concepts developed. The following SoS concepts were selected and evaluated, with the results shown in Figure 4. The RSME for SoS evaluation was 0.0538, which again shows close outcome between the two methods of evaluation. 
ISAHP Article: A Style Guide for Paper Proposals To Be Submitted to the International Symposium on the Analytic Hierarchy Process 2018, Hong Kong, HK.

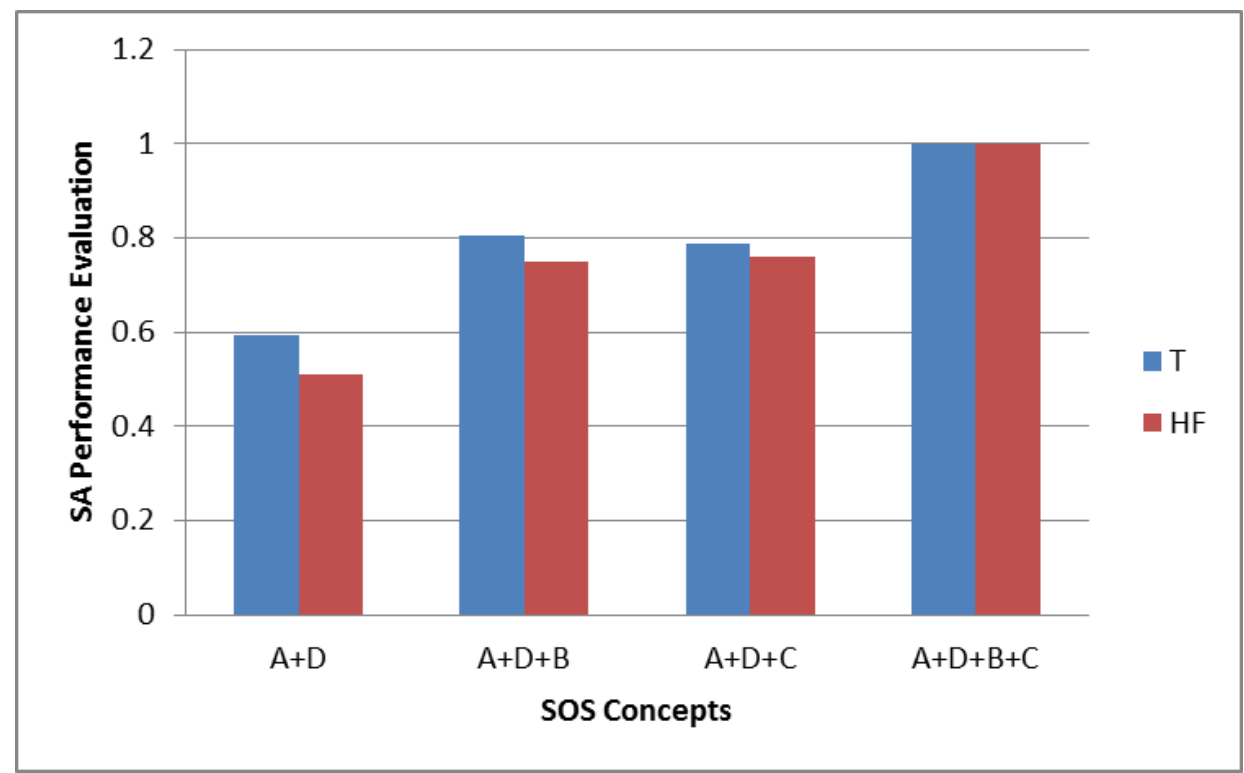

Figure 4. System-of-Systems level evaluation

\section{Conclusions}

This paper presented a methodology based on AHP to evaluate SoS SA concept effectiveness using both technical and HF criteria that are complimentary in nature. An evaluation process is conducted based on technical and human factors with feedback to ensure mission requirements are met. The system level evaluation is applied using the AHP and those results are used in the SoS evaluation. Although the importance of each of the technical and HF criteria towards the overall evaluation of the SoS concept will be weighted based on the context within which the SoS concept is being evaluated, each type of assessment represents a quality control check on the other assessment thereby providing a more robust and precise assessment of the SoS concept than if these criteria isolated.

\section{Key References}

Saaty, T.L. (1995), Decision Making for Leaders: The Analytic Hierarchy Process for Decisions in a Complex World. RWS Publications, Pittsburgh, PA, USA.

Jassemi-Zargani, R., Kashyap, N. (2013), Assessing Systems of Systems' Performance Using a Hierarchical Evaluation Process, ISAHP2013, Kuala Lumpur, Malaysia. 